\title{
AEROMAGNETIC MAP OF THE EAST-CENTRAL PART OF THE DEATH VALLEY NATIONAL MONUMENT INYO COUNTY, CALIFORNIA \\ By
}

G. E. Andreasen and F. A. Petrafeso

GEOPHYSICAL INVESTIGATIONS

MAP GP-428

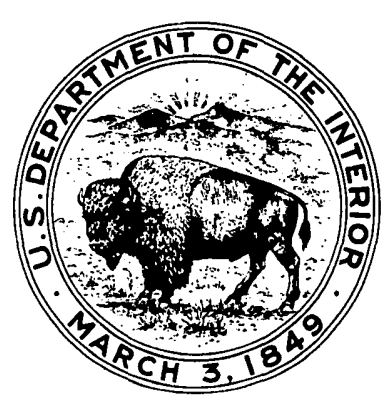

